\title{
FINITE VOLUME NUMERICAL METHODS FOR AEROHEATING RATE CALCULATIONS FROM INFRARED THERMOGRAPHIC DATA
}

\author{
Kamran Daryabeigi, ${ }^{*}$ Scott A. Berry, ${ }^{+}$Thomas J. Horvath, ${ }^{\ddagger}$ and Robert J. Nowak ${ }^{\S}$ \\ NASA Langley Research Center \\ Hampton, Virginia 23681
}

\begin{tabular}{|c|c|}
\hline Abstract & $\begin{array}{ll}\mathrm{H} & \text { enthalpy, } \mathrm{J} / \mathrm{kg} \\
\mathrm{k} & \text { thermal conductivity, } \mathrm{W} / \mathrm{m} / \mathrm{K}\end{array}$ \\
\hline The use of multi-dimensional finite volume numerical & L length, $\mathrm{m}$ \\
\hline techniques with finite thickness models for calculating & $\mathrm{L}_{\mathrm{x}}$ length of $1^{\text {st }}$ Macor insert \\
\hline aeroheating rates from measured global surface & $\mathrm{L}_{\mathrm{y}}$ width of $1^{\text {st }}$ Macor insert \\
\hline temperatures on hypersonic wind tunnel models was & $\mathrm{L}_{\mathrm{z}}$ thickness of Macor inserts \\
\hline investigated. Both direct and inverse finite volume & $\mathrm{q}^{\prime \prime}$ heat flux, W/m \\
\hline techniques were investigated and compared with the & $\mathrm{T}$ temperature, $\mathrm{K}$ \\
\hline one-dimensional semi-infinite technique. Global & $\mathrm{T}_{\mathrm{o}}$ initial (pre-run) temperature, $\mathrm{K}$ \\
\hline $\begin{array}{l}\text { transient surface temperatures were measured using an } \\
\text { infrared thermographic technique on a } 0.333 \text {-scale }\end{array}$ & $\begin{array}{l}\mathrm{t} \text { run time (measured from initiation of model } \\
\text { injection), } \mathrm{s}\end{array}$ \\
\hline model of the Hyper-X forebody in the Langley & $\mathrm{t}_{1}$ time model is at test section centerline, $\mathrm{s}$ \\
\hline Research Center 20-Inch Mach 6 Air tunnel. In these & $\mathrm{t}_{\text {corr }}$ correction time, $\mathrm{s}$ \\
\hline tests the effectiveness of vortices generated via gas & $\mathrm{t}_{\mathrm{eff}}$ effective time, $\mathrm{s}$ \\
\hline injection for initiating hypersonic transition on the & S sum of square of errors \\
\hline Hyper-X forebody were investigated. An array of & $\mathrm{x}$ local coordinate along model length \\
\hline streamwise orientated heating striations were generated & local coordinate along model width \\
\hline $\begin{array}{l}\text { and visualized downstream of the gas injection sites. In } \\
\text { regions without significant spatial temperature }\end{array}$ & z local coordinate along model thickness \\
\hline gradients, one-dimensional techniques provided & $\alpha$ thermal diffusivity, $\mathrm{m}^{2} / \mathrm{s}$ \\
\hline accurate aeroheating rates. In regions with sharp & $\beta$ thermal product, $\sqrt{\rho c k}, \mathrm{~J} / \mathrm{m}^{2} / \mathrm{K} / \mathrm{s}^{0.5}$ \\
\hline $\begin{array}{l}\text { temperature gradients due to the striation patterns two- } \\
\text { dimensional heat transfer techniques were necessary to }\end{array}$ & $\rho \quad$ density, $\mathrm{kg} / \mathrm{m}^{3}$ \\
\hline obtain accurate heating rates. The use of the one- & $\underline{\text { Subscripts }}$ \\
\hline dimensional technique resulted in differences of $\pm 20 \%$ & aw adiabatic wall condition \\
\hline in the calculated heating rates because it did not & t1 reservoir conditions \\
\hline account for lateral heat conduction in the & t2 stagnation conditions behind normal shock \\
\hline$\underline{\text { Nomenclature }}$ & $\begin{array}{l}\mathrm{w} \quad \text { wall condition } \\
\infty \quad \text { freestream static condition }\end{array}$ \\
\hline c specific heat, $\mathrm{J} / \mathrm{kg} / \mathrm{K}$ & Acronyms \\
\hline Fo Fourier number & SI semi-infinite \\
\hline $\begin{array}{l}\mathrm{h} \text { enthalpy-based heat transfer coefficient, } \mathrm{kg} / \mathrm{m}^{2} / \mathrm{s} \\
\mathrm{h}_{\text {ref }} \text { reference heat transfer coefficient, } \mathrm{kg} / \mathrm{m}^{2} / \mathrm{s}\end{array}$ & $\mathrm{FV}$ finite volume \\
\hline
\end{tabular}

\footnotetext{
* Aerospace Technologist, Metals and Thermal Structures Branch, MS 396, Senior Member AIAA

${ }^{+}$Aerospace Technologist, Aerothermodynamics Branch, MS 408A,

¥ Aerospace Technologist, Aerothermodynamics Branch, MS 408A

${ }^{\S}$ Research Scientist, Aerothermodynamics Branch, MS 408A, Member AIAA

This material is declared a work of the U.S. Government and is not subject to copyright protection in the United States.
} 


\section{Introduction}

One of the standard techniques for calculating aeroheating rates from measured transient surface temperatures on hypersonic wind tunnel models has been the one-dimensional semi-infinite solid conduction method. This method was originally developed for use with discrete temperature sensors, such as thin film resistance gages. ${ }^{1}$ The semi-infinite analysis assumes that heat doesn't noticeably diffuse to the back surface of the model, so that the back surface temperature doesn't vary. It is also assumed that there is no lateral heat conduction so that heat is conducted only in the direction of the model thickness from the top surface (surface exposed to aeroheating) to the back surface. This assumption is necessary when using discrete temperature sensors, since due to limitations on the number and spacing of the sensors that can be installed on the model multidimensional conduction cannot be considered. There are several limitations to the use of the 1-D semi-infinite method. The semiinfinite assumption is only valid for a specific time duration that is a function of model thickness and thermophysical properties. The solution assumes constant thermophysical properties. Furthermore, this technique is not suitable for regions with sharp temperature gradients across the surface, because lateral heat conduction may be significant compared to through-the-thickness heat conduction.

To overcome limitations on the number of discrete sensors that can be installed on models, optical techniques such as infrared and phosphor thermal imaging have been utilized for providing global aeroheating data on hypersonic wind tunnel models. The phosphor thermography technique is routinely used at Langley Research Center for hypersonic wind tunnel aeroheating measurements. ${ }^{2}$ The accuracy of infrared thermal imaging for transient surface temperature measurements on a flat plate model in subsonic flow has been evaluated by comparison with surface mounted thermocouples. ${ }^{3}$ This technique has been used for aeroheating calculations on hypersonic wind tunnel models, ${ }^{4,5}$ and for in -flight surface temperature measurements on the Shuttle Orbiter. 6 ,

The 1-D semi-infinite technique is the standard method used with thermal imaging techniques, even though the availability of whole -field surface temperature distributions lends itself to using multidimensional thermal analysis. The 1-D semi-infinite method yields a simple analytical solution, ${ }^{8}$ while multi-dimensional solid conduction analysis requires numerical thermal analysis software and complete modeling of the geometry of the wind tunnel model. Nevertheless, the 1-D semi-infinite model has produced satisfactory results on blunt body configurations. ${ }^{2}$
Future vehicles, such as air-breathers, are slender with thin forebody/control surface leading edges. In addition, there is a critical need for more detailed studies of micro aerothermodynamic phenomena (such as vortices and protuberances). The 1-D semi-infinite technique is not adequate to accurately assess these issues with future vehicles. The present study is an attempt to investigate use of numerical multidimensional heat conduction models with global thermal data as the next level of data reduction methods.

Numerical techniques have been previously used with discrete sensors to overcome some of the 1-D semi-infinite limitations. The 1-D finite volume numerical technique has been used for calculating aeroheating rates from discrete sensors on hypersonic wind tunnel models. ${ }^{9,10}$ This technique numerically solves the governing diffusion equation using the measured temperatures on the top surface and assuming an adiabatic back face boundary condition. The main advantage of this technique is that it can use temperature-varying properties and it does not have the time limitation validity issues associated with the semiinfinite technique. An inverse 2-D finite element numerical technique has been used in conjunction with temperature measurements from a linear array of closely spaced thin film gages to obtain heating rate distributions in the region of shock impingement on a cylinder in Mach 6 flow. ${ }^{11}$ This technique resulted in higher peak heating rates at shock impingement locations, but the accuracy of the technique could not be determined due to limitations on the number of sensors used.

In order to investigate multi-dimensional finite volume numerical techniques with global thermal imaging data, a series of runs were conducted as a subset of an overall experimental program for evaluating gas injection for tripping the boundary layer on a 0.333 -scale Hyper-X forebody model. This tripping mechanism produces an array of streamwise orientated heating striations downstream of the gas injection sites. Various solid trip configurations had previously been investigated on this 0.333 - scale Hyper-X forebody model. ${ }^{12}$ The overall test program was a comprehensive study to investigate the effectiveness of gas injection for hypersonic boundary layer transition and included more than 80 wind tunnel runs. It used phosphor thermography for aeroheating measurements and included oil flow visualization runs. The runs reported here were a small subset of the overall test program and concentrated on evaluation of multi-dimensional solid conduction numerical methods in conjunction with infrared thermographic techniques to study the striation heating downstream of the gas injection sites. 
The main objective of this investigation was to compare 1-D and multi-dimensional finite volu me methods for predicting heating rates, especially in regions with large spatial temperature gradients. Both direct and inverse finite volume techniques were investigated.

\section{Experimental Methodology}

\section{Test Facility}

Aeroheating data were obtained on a 0.333 -scale Hyper-X forebody model in the 20-Inch Mach 6 Air Tunnel of the LaRC Aerothermodynamics Laboratory. ${ }^{13}$ This tunnel is a conventional blowdown tunnel with a $0.521 \mathrm{~m} \times 0.508 \mathrm{~m}(20.5 \times 20$ in. $)$ test section, and uses a two-dimensional contoured nozzle to provide a nominal freestream Mach number of 6 . The tunnel uses dried, heated, filtered air as the test gas. A detailed description of the facility and its associated instrumentation is found in Ref. 13. Typical operating conditions for the tunnel are stagnation pressures of 0.21-3.45 MPa, stagnation temperatures of 483-533 K, and free stream unit Reynolds numbers of $1.6 \times 10^{6} / \mathrm{m}$ $25.6 \times 10^{6} / \mathrm{m}$. A bottom-mounted model injection system inserts models from a sheltered position to the tunnel centerline in approximately $1-2 \mathrm{~s}$. Typical duration of aeroheating tests in this facility is 5-10 s.

\section{Model}

A photograph of the 0.333-scale Hyper-X forebody model is shown in Fig. 1. This model is described in detail in Ref. 12, and was previously used for comparing the effectiveness of various hypersonic boundary-layer trip devices. ${ }^{12}$ The windward forebody model consisted of three flat ramps that provided a series of discrete nonisentropic flow compression surfaces simulating the engine external inlet ramps. The model was tested at $2^{\circ}$ angle of attack, and the first, second and third ramps provided additional compressions of $2.5^{\circ}, 5.5^{\circ}$, and $3^{\circ}$, respectively.

The forebody model, 71.12-cm long, was built from aluminum and had a detachable stainless-steel leading edge (nose radius of $0.254 \mathrm{~mm}$ ) and interchangeable measurement surface inserts. The length of the leading edge was $12.7-\mathrm{cm}$, while the trip station was $18.84-\mathrm{cm}$ from the model leading edge. The trip insert plates consisted of several stainless steel inserts with various orifice shapes and spacing for gas injection into the flow in order to trip the boundary layer. The specific trip insert plate used for this report consisted of a single row of 17 orifices, $0.25-\mathrm{mm}$ in diameter with a $3.18-\mathrm{mm}$ spacing. The re maining flat ramp sections were designed to accommodate either a
Macor ${ }^{*}$ or aluminum set of inserts. The Macor and aluminum inserts were used for heat transfer and flow visualization studies, respectively. The Macor inserts were $6.35-\mathrm{mm}$ thick. The leading edge of the first insert plate, $10.87-\mathrm{cm}$ long and $12.9-\mathrm{cm}$ wide, was 20.74-cm downstream of the model leading edge. Since phosphor thermography was the main measurement system used for obtaining heating rates for the overall experimental program, the Macor substrates were coated with a $0.025-\mathrm{mm}$ thick mixture of phosphors suspended in a silica-based colloidal binder. A photograph of part of the model showing the leading edge, the trip insert plate with 17 orifices for gas injection, and the first Macor in sert is shown in Fig. 2 .

\section{Test Conditions}

The nominal reservoir stagnation pressure and temperature for the two runs reported in the present study are presented in Table 1 . The reported flow conditions were based on the measured reservoir stagnation pressures and temperatures and recent unpublished tunnel calibrations. Both runs were conducted with the model at an angle of attack of $2^{\circ}$. Run 70 was a baseline test without gas injection into the boundary layer, while Run 71 consisted of gas injection into the boundary layer. The total pressure of the gas injected into the boundary layer was measured in a manifold directly below the orifices, and was $31.2 \mathrm{kPa}$. The total pressure was used to control the penetration depth of the jets compared to the boundary layer thickness.

\section{Test Technique}

Model surface temperatures were measured using an infrared imaging system with an un-cooled microbolometer-based focal plane array detector with $320 \times 240$ detector elements. The imager has a field of view of $24^{\circ} \times 18^{\circ}$, and is sensitive to infrared radiation emitted in the 7-12 micrometer spectral range of the electromagnetic spectrum. An eight-inch diameter zinc selenide window with proper anti-reflection coating to provide transmittance of 0.98 in the 7-14 micrometer spectral range was used for optical access to the test section. The measured infrared radiation is converted to actual surface temperatures using the emittance of target. Ceramic models have high emittance values and do not require any special coating for infrared thermal measurements. But the Macor inserts used in this test had already been coated with phosphor coating to obtain global thermographic phosphor data in subsequent tunnel runs. The roomtemperature, total (wavelength averaged), near normal emittance of the

\footnotetext{
* a machinable glass ceramic which is a registered trademark of Corning Incorporated
} 
Macor inserts with the applied surface phosphor coating was determined to be 0.88 using a heated cavity reflectometer. ${ }^{14}$ Joints between the Macor inserts corresponding to the location of ramp angle changes (Fig. 1) were used to geometrically locate the model in image mappings. The imager produces 30 frames of images per second, while the data acquisition hardware used was only capable of real-time digital storage of approximately 6 frames per second. Surface temperatures were measured on parts of the model leading edge, the entire first Macor insert, and part of the second Macor insert. But only the data from the first Macor insert was used in this study to compare various aeroheating calculation techniques. Model surface streamlines were obtained using the oil flow technique. Metal inserts were used on the model and were spray painted with black paint to enhance contrast with the white-pigmented oil. Surface streamlines were recorded using a conventional video camera. ${ }^{12}$

\section{Solution Techniques}

\section{1-D Semi-Infinite Method}

The standard 1-D semi-infinite solid conduction formulation with specified surface temperature boundary condition cannot be used with global optical techniques in hypersonic wind tunnels with model injection since detailed surface temperature data is not available during the time the model is being injected into the test section. Imagers are set such that they are focused on the model after the model has reached the centerline position in the test section. Furthermore, with optical techniques requiring ultraviolet excitation of the target, the model might not be completely and uniformly illuminated till it reaches the test section centerline. Therefore, the semi-infinite solid conduction formulation with convective bound ary condition has been utilized for global thermographic measurement techniques. ${ }^{2}$ The governing equation is the constant property $1-\mathrm{D}$ heat conduction equation, with an enthalpy-based convective boundary condition

$$
-k \frac{\partial T}{\partial z}(0, t)=h\left[H_{a w}-H_{w}\right]
$$

$\mathrm{H}_{\mathrm{aw}}$ is the adiabatic wall enthalpy assumed to be equal to the total enthalpy $\left(\mathrm{H}_{\mathrm{T} 1}\right.$ in Table 1$)$, and $\mathrm{H}_{\mathrm{w}}$ is the wall enthalpy evaluated at wall temperature $\left[\mathrm{T}_{\mathrm{w}}=\mathrm{T}(0, \mathrm{t})\right]$. The analytical solution is

$$
\begin{aligned}
T(z, t)= & T_{0}+\left[H_{a w} \frac{T(0, t)}{H_{w}}-T_{0}\right] \\
& {\left[\operatorname{erfc}(\eta)-e^{\frac{h H_{w} z}{T(0, t) k}+\lambda^{2}} \operatorname{erfc}(\lambda+\eta)\right] }
\end{aligned}
$$

where $T_{0}$ is the initial temperature, and

$$
\begin{gathered}
\eta=\frac{z}{2 \sqrt{\alpha t}} \\
\lambda=\frac{h H_{w} \sqrt{t}}{T(0, t) \beta} \\
\beta=\sqrt{\rho c k}
\end{gathered}
$$

where $e r f c$ is the complimentary error function. At the surface $(z=0)$, the solution reduces to

$$
\frac{T(0, t)-T_{o}}{\frac{H_{a w}}{H_{w}} T(0, t)-T_{0}}=1-e^{\lambda^{2}} \operatorname{erfc} \lambda
$$

The measured surface temperature is used in Eq.(4) to solve for $\lambda$, which then yields the heat transfer coefficient, $h$, from Eq. (3.b). Since the formulation is for constant temperature thermophysical properties, calculations are made using temperature-averaged properties. ${ }^{2}$ The above calculations are performed for every point (pixel) in the image. All that is needed to compute heat transfer coefficient distributions over the model is the initial surface temperature distribution, one test image, and the corresponding time. This technique assumes that the heat transfer coefficient distribution is time invariant. This assumption is not valid when the model is traversing through the test section's boundary layer. In order to overcome this difficulty, the injection process is modeled as a delayed step heating, with the delay in the step corresponding to the time when the model has traversed halfway through the tunnel boundary layer. ${ }^{2}$ The time it takes from the initiation of the injection process until the model traverses halfway through the tunnel boundary layer edge is referred to as the "correction time", $\mathrm{t}_{\text {corr }}$, and is subtracted from the run time to obtain an effective time to be used in the above equations $^{2}$

$$
t_{\text {eff }}=t-t_{\text {corr }}
$$

where $t$ is the actual run time which is triggered when the injection system first starts to move. The calculation of $\mathrm{t}_{\text {corr }}$ is described in detail in Ref. 2. This technique has been validated by aeroheating calculations on a $50.8-\mathrm{mm}$ diameter hemisphere in Mach 10 flow, ${ }^{2}$ and has been successfully applied to typical blunt body configurations such as $\mathrm{X}-34^{2}$ and $\mathrm{X}$ $33^{15}$ with favorable comparisons with computational fluid dynamic (CFD) calculations.

\section{Finite Volume Numerical Technique}

As mentioned previously only the data from the first Macor insert are discussed in this study in order to simplify geometrical considerations and concentrate on the basic aeroheating calculation issues. Referring to Fig. 3 for local coordinate system and geometrical definitions, the governing 3-D diffusion equation and initial and boundary conditions used for the Macor insert were 


$$
\begin{gathered}
\rho \mathrm{c} \frac{\partial T}{\partial \mathrm{t}}=\frac{\partial}{\partial \mathrm{x}}\left(k \frac{\partial T}{\partial \mathrm{x}}\right)+\frac{\partial}{\partial y}\left(k \frac{\partial T}{\partial \mathrm{y}}\right)+\frac{\partial}{\partial z}\left(k \frac{\partial T}{\partial \mathrm{z}}\right) \\
T\left(x, y, x, t_{1}\right)=g(x, y, z) \\
T(x, y, 0, t)=f(x, y, t) \\
\frac{\partial T}{\partial z}\left(x, y, L_{z}, t\right)=0 \\
\frac{\partial T}{\partial y}(x, 0, z, t)=0 \\
\frac{\partial T}{\partial y}\left(x, L_{y}, z, t\right)=0 \\
\frac{\partial T}{\partial x}(0, y, z, t)=0 \\
\frac{\partial T}{\partial x}\left(L_{x}, y, z, t\right)=0
\end{gathered}
$$

These equations are valid for $\mathrm{t} \geq \mathrm{t}_{1}$, with $\mathrm{t}_{1}$ corresponding to run time when the model has reached the test section centerline, since detailed surface temperature data are only available after this time. For simplicity it was assumed that adiabatic boundary conditions existed at the edges of the Macor insert ( $\mathrm{y}=$ $0, y=L_{y}, x=0$, and $x=L_{x}$ ), Eqs. (6.e)-(6.h). Actually, heat is transferred from the edges of the first Macor insert to the adjoining surfaces on the model (metallic surfaces or second Macor insert), but the exact modeling of these boundary conditions was not necessary, since the imposed boundary conditions do not significantly affect heat transfer in the region of interest away from the boundaries. It was assumed that the model back face $\left(\mathrm{z}=\mathrm{L}_{\mathrm{z}}\right)$ is adiabatic [Eq. (6.d)], while the top surface has a specified transient temperature distribution, $\mathrm{f}(\mathrm{x}, \mathrm{y}, \mathrm{t})$, measured using the optical thermographic technique [Eq. (6.c)]. The Macor inserts were placed on the model using narrow spacers, resulting in air gaps between the back face of the inserts and the top of the metallic model. Therefore, the adiabatic back face boundary condition was utilized. This assumption is certainly valid during the time the semi -infinite assumption is valid. Furthermore, after the back face temperature begins to rise, the heat losses from the back face are typically low enough that the assumption of an adiabatic condition may not introduce large errors The initial temperature distribution through the thickness of the model at time $\mathrm{t}=\mathrm{t}_{1}$ is represented as $\mathrm{g}(\mathrm{x}, \mathrm{y}, \mathrm{z})$. This initial temperature distribution was not known for $\mathrm{z}>0$, and the $\mathrm{z}$ variation was approximated at each pixel location by the analytical solution of 1-D semi-infinite conduction model, Eq. (2), at time $t_{1}$. Any errors in this initial temperature distribution will be corrected after a few time steps of the numerical solution due to the diffusive nature of heat conduction.
The governing equations for the 2-D and 1-D finite volume techniques are subsets of the set of equations provided in Eqs. (6.a)-(6.h). For the 1-D case the dependence on $x$ and $y$ coordinates and the corresponding boundary conditions in these directions are eliminated. For the 2-D case the dependence on $x$ coordinate and the corresponding boundary conditions in this direction are eliminated. The solution to this set of equations constitutes the direct solution method. The equations were solved using a finite volume numerical method with variable thermophysical properties. The transient problem was solved using unconditionally stable implicit time marching techniques: $:^{16}$ Crank Nicholson method for the 1-D case and AlternatingDirection Implicit (ADI) method for the 2-D and 3-D cases. The governing equations and the derivative boundary conditions were formulated such that secondorder accuracy could be achieved with truncation errors on the order of $\Delta \mathrm{t}^{2}$ and $\Delta \mathbf{x}^{2}$, where $\Delta \mathrm{t}$ and $\Delta \mathbf{x}$ are the time step and spatial nodal spacing, respectively. For the results reported here 21 nodes were used in the $\mathrm{z}$ direction, and 128 by 159 nodes in the $\mathrm{y}$ and $\mathrm{x}$ directions, respectively. The latter was dictated by the number of infrared image pixels across the top surface of the first Macor insert. Solutions obtained using 51 and 21 nodes in the $\mathrm{z}$ direction were similar, thus verifying that the nodal spacing used was sufficient. The time step used was dictated by the digital storage interval of infrared images, which was approximately $0.17 \mathrm{~s}$. Upon numerical solution of the governing equations, the convective heat transfer coefficient was calculated at each instant of time from

$$
\begin{aligned}
-k \frac{\partial T}{\partial z}(x, y, 0, t)= & h(x, y, t) \\
& {\left[H_{a w}-H_{w}(x, y, t)\right] }
\end{aligned}
$$

For the inverse method, the conservation of energy equation, Eq. (6.a) was solved subject to all the initial and boundary conditions stated above, except that the specified temperature boundary condition on top surface, Eq. (6.c), was replaced by the convective boundary condition in Eq. (6.i), and it was assumed that the convective heat transfer coefficient was independent of time. Since the convective heat transfer coefficients were unknown, the Levenberg-Marquardt method for nonlinear parameter estimation ${ }^{17}$ was utilized to estimate their values. The inverse technique is an iterative numerical scheme where a matrix $\boldsymbol{h}$ of estimates representing $\mathrm{h}(\mathrm{x}, \mathrm{y})$ is assumed; the numerical solution to the equation using this boundary condition and previously described boundary and initial conditions are marched in time, and surface temperature distributions are calculated. The comparison of measured and calculated transient surface temperatures and the Jacobian matrix representing the derivatives of surface temperatures with respect to the heat transfer 
coefficients are used to develop better estimates of $\boldsymbol{h}$. This iterative procedure is based on the minimization of the ordinary least squares norm given by

$$
S=\sum\left[T_{m}(x, y, 0, t)-T_{p}(x, y, 0, t)\right]^{2}
$$

where $T_{m}$ and $T_{p}$ are measured and calculated surface temperatures, respectively. The 1-D inverse method required estimating one heat transfer coefficient at each measurement point on the image. The 2-D and 3-D inverse methods required simultaneous estimation of either an array of heat transfer coefficient along a specific axis, or a matrix of heat transfer coefficients over the entire image, respectively. The computational effort increases tremendously as analysis is extended from 2-D to 3-D.

For the inverse method, transient solution could be obtained at time steps smalle $r$ than the time increment at which surface temperature distributions were available, but the comparison of predicted and measured temperatures, required in Eq. (7), was performed at times when surface temperature data were available.

\section{$\underline{\text { Results and Discussion }}$}

Results for the baseline run without gas injection (Run 70) are presented to compare various techniques for calculating aeroheating rates. Then the results for the run with gas injection (Run 71) are presented. Macor thermophysical properties were obtained from published results in Ref. 9. The convective heat transfer rates were non-dimensionalized with respect to a reference heat transfer coefficient, $h_{\text {ref }}$, corresponding to the Fay and Riddell ${ }^{18}$ stagnation-point heating on a 101.6-mm radius sphere. The standard data reduction procedure for conducting aeroheating tests using global thermographic techniques was used. The model was injected into the test section just prior to establishing tunnel flow and a "pre -run" image of initial surface temperature distribution across the model was obtained. Then the model was retracted. After the flow was established, the model was injected into the test section, and the start of the injection process triggered the infrared imaging digital recording process at $0.17 \mathrm{~s}$ intervals. Only the surface temperature and aeroheating results on the first Macor insert are presented.

\section{Run without Gas Injection}

The run without gas injection provided uniform surface temperature and aeroheating distributions across most of the surface area of the $1^{\text {st }}$ Macor insert. Therefore, this run was utilized to assess the accuracy of 1-D and multi-dimensional direct and inverse finite volume methods. The initial (pre-run) average surface temperature on the first Macor insert was $303.7 \mathrm{~K}$ with a standard deviation of $\pm 0.28 \mathrm{~K}$. Run time of $1.37 \mathrm{~s}$ corresponded to the time when the first image was digitally recorded after the model had reached the test section centerline. The spatial distribution of surface temperature rise compared to initial temperature along the centerline of the forebody model $\left(\mathrm{y}=\mathrm{L}_{\mathrm{y}} / 2\right)$ at various times throughout the run is shown in Fig. 4. Data are plotted versus the non-dimensional length, $\mathrm{x} / \mathrm{L}_{\mathrm{x}}$. The surface temperatures rose only $6.1 \mathrm{~K}$ after 8.5 $\mathrm{s}$ for this low aeroheating condition; i.e., a slender body at a low angle of attack $\left(2^{\circ}\right)$ and at unit Reynolds number of $7.3 \times 10^{6} / \mathrm{m}$. The adverse pressure gradient provided by the second ramp induced a local flow separation near the end of the first Macor insert, as is evident from the sharp decrease of surface temperatures, especially at later times.

The spatial variation of non-dimensional convective heat transfer rates along the model centerline $\left(\mathrm{y}=\mathrm{L}_{\mathrm{y}} / 2\right)$ calculated using various $1-\mathrm{D}$ techniques is shown in Fig. 5: semi-infinite, direct and inverse finite volume results. The semi-infinite and direct finite volume results shown are at $\mathrm{t}=2.58 \mathrm{~s}$. Semi-infinite results are presented both with and without time corrections, Eq. (5). Originally, the semi infinite results were calculated using the standard technique $^{2}$ with the appropriate time correction, which for the runs reported here was $0.89 \mathrm{~s}$. But comparison of the results with other experimental results showed that these results were over-predicting the other results significantly. Therefore, semi-infinite results were also calculated with $t_{\text {corr }}=0 \mathrm{~s}$ which better agreed with other results. It appears that the use of time correction with semi-infinite techniques is not applicable to wind tunnel tests on slender bodies at low heating rates. Therefore, for the direct and inverse finite volume numerical methods, the initial temperature distribution at $t=t_{1}=1.37 \mathrm{~s}$, was calculated from the semi-infinite solution, Eq. (2), with $t_{\text {corr }}=0$. The inverse results shown in Fig. 5 were calculated using temperature data from 6 thermal images with $0.17 \mathrm{~s}$ time steps with the first image at $1.37 \mathrm{~s}$. Using 6 thermal images with 0.34 $\mathrm{s}$ time steps and 12 thermal images at $0.17 \mathrm{~s}$ time steps yielded similar results. Overall, there was good agreement between direct and inverse finite volume results. The semi -infinite results with no time correction slightly over-predicted the finite volume results, while the semi -infinite results with time correction were significantly higher than all the other results.

The temporal variation of the heat transfer coefficients spatially averaged over the interval $0 \leq x \leq$ $\mathrm{L}_{\mathrm{x}}$ along the model centerline $\left(\mathrm{y}=\mathrm{L}_{\mathrm{y}} / 2\right)$ using semiinfinite technique with and without time correction and direct and inverse finite thickness numerical results are shown in Fig. 6. The semi -infinite technique with time correction over-predicted the heating rates significantly 
at early times, then, asymptotically approached a constant value. The semi-infinite technique with no time correction slightly over-predicted the heating rates at early times, and quickly leveled off. The semiinfinite results are very sensitive to correction time, especially at early times. Even though the semi -infinite results with time correction provided correct results after $\mathrm{t}=6 \mathrm{~s}$, the validity of the semi-infinite assumption at this time is questionable. The semi-infinite assumption for a convective boundary condition is valid for $^{19}$

$$
F o=\frac{\alpha t}{L_{z}^{2}} \leq 0.097
$$

With Macor thermophysical properties at room temperature and a model thickness of $6.35 \mathrm{~mm}$, the semi -infinite assumption is only valid for $t \leq 4.9$ s. So, even though reducing data at later times $(t \geq 6 \mathrm{~s})$ might produce accurate results, but the basic assumption used in the analytical solution is violated. The direct finite volume results also slightly over-predicted the heating rates at early times, and then slightly oscillated around a constant value at later times. The inverse finite volume technique generated time independent results which all the other techniques' results eventually approached.

The direct and inverse 1-D finite volume results described previously were obtained by using the semi infinite solution without time correction as the initial temperature distribution $\left(t=t_{1}\right)$ through the thickness of the model. The sensitivity of the inverse 1-D finite volume result to this initial temperature distribution was investigated by comparing this result to one when time correction was used for the initial temperature distribution at a point at the center of the $1^{\text {st }}$ Macor insert, $\mathrm{x}=\mathrm{L}_{\mathrm{x}} / 2, \mathrm{y}=\mathrm{L}_{\mathrm{y}} / 2$. The resulting convective heat transfer coefficients with and without time corrections for the initial temperature distribution were 0.12 and 0.11 , respectively. Therefore, the inverse finite volume technique appears to be fairly insensitive to the initial temperature distribution used.

The variation of convective heat transfer coefficients with $y / L_{y}$ at $x / L_{x}=0.75$ calculated using one, two, and three dimensional direct finite volume formulations are presented in Fig. 7. The 2-D results were calculated at each longitudinal position across the width of the model from $y / \mathrm{L}_{\mathrm{y}}=0$ till $\mathrm{y} / \mathrm{L}_{\mathrm{y}}=1$. For the two-dimensional case the dependence on $x$ coordinate and the corresponding boundary conditions in this direction were eliminated. The three sets of results coincided with each other except at the edges $\left(\mathrm{y} / \mathrm{L}_{\mathrm{y}}=0\right.$ and 1 ), where the 2-D and 3-D results slightly varied from 1-D results due to the imposition of the adiabatic boundary conditions at the edges for the multidimensional formulations. This showed that the baseline case had no in-plane gradients of a magnitude affecting the calculations, and that for this case 1-D analysis was sufficient.

\section{Run with Gas Injection}

A run was conducted with gas injection into the boundary layer for tripping the boundary layer flow. A photograph of the oil flow visualization for a run with similar flow conditions is shown in Fig. 8. The orifices for gas injection, and the streamlines corresponding to 18 vortices downstream of the gas injection sites are visible in the photograph. Each gas injection orifice produced two vortices, with the two vortices between adjacent orifices merging together, thus, producing 18 vortices for this 17-orifice configuration. A contour plot of the corresponding non-dimensionalized convective heat transfer coefficients calculated using the inverse 1-D finite volume technique is shown in Fig. 9. The traces of 18 streamwise oriented heating striations downstream of the gas injection sites are visible in the contour plot. The heating results were consistent with oil flow results in a qualitative sense.

It was believed that in the vicinity of the vortices with high spatial temperature gradients $1-\mathrm{D}$ heating results might not be accurate, therefore, multidimensional finite volume techniques were utilized. First, direct 2-D and 3-D direct finite volume techniques were compared to determine which formulation would be more appropriate for the given run conditions. The $2-\mathrm{D}$ results were calculated at each longitudinal position across the width of the model from $\mathrm{y} / \mathrm{L}_{\mathrm{y}}=0$ till $\mathrm{y} / \mathrm{L}_{\mathrm{y}}=1$ (the dependence on $x$ coordinate and the corresponding boundary conditions in this direction were eliminated). The comparison of the results at the longitudinal position of $\mathrm{x} / \mathrm{L}_{\mathrm{x}}=0.25$ is shown in Fig. 10. The heating peaks related to the 18 vortices are visible between $y / L_{y}$ of 0.2 and 0.8 . The heating rates at some vortex locations are as high as 3 times the heating rates in the undisturbed regions. Furthermore, it is seen that there is no difference between the heating results predicted using either the 2 $\mathrm{D}$ or 3-D analysis, with the root mean square difference between the two sets of results being $1 \%$. Therefore, it was determined that a 2-D analysis is sufficient for obtaining heating rates for this run. It was also desirable to use the inverse method since it yields timeinvariant heat transfer coefficients. Therefore, 2-D inverse finite volume analysis was used for the rest of the study. The comparison of 1-D and 2-D inverse finite volume results for the longitudinal positions of $\mathrm{x} / \mathrm{L}_{\mathrm{x}}$ of 0.25 and 0.5 are shown in Figs. 11.a and 11.b, respectively. The $1-\mathrm{D}$ results under-predict the actual heating rates at the peak heating locations, and overpredict the heating rates in the valleys between two adjacent peaks. Lateral heat conduction smears the surface temperature distribution in regions with sharp heating gradients; heat gets transferred from the peaks 
to the valleys, causing reduction of temperature at the peak and increase of temperature at the valleys. When 1-D heat transfer is utilized with the measured temperature distributions, the predicted heating rates are lower at the peaks and higher at the valleys. Only multidimensional, in this case 2-D, heat transfer analysis can predict the correct heating magnitudes, since it accounts for lateral heat conduction. Any noise in the measured surface temperatures gets amplified in the estimation of the heating rate, and regularization techniques have previously ${ }^{11,20}$ been used utilized with inverse techniques to overcome this problem. In the present study the noise in the measured surface temperatures did not pose a major problem for heating rate calculations, and no regularization technique was used. The difference between heating rates calculated using 1-D and 2-D methods along the $\mathrm{y}$ axis at longitudinal positions of $\mathrm{x} / \mathrm{L}_{\mathrm{x}}$ of 0.25 and 0.5 are shown in Figs. 12.a and 12.b, respectively. The 1-D method under-predicts and over-predicts the heating rates at the peaks and valley by almost $20 \%$.

\section{Concluding Remarks}

Global transient surface temperatures were measured using an infrared thermographic technique on a 0.333 -scale model of the Hyper- $\mathrm{X}$ forebody in the Langley Research Center 20-Inch Mach 6 Air tunnel. In these tests the effectiveness of vortices generated via gas injection for initiating hypersonic transition on the Hyper-X forebody were investigated. An array of streamwise orientated heating striations were generated and visualized downstream of the gas injection sites. The striation patterns were attributed to the development of embedded boundary layer vortices. The use of multi-dimensional numerical finite volume numerical techniques for calculating aeroheating rates from measured global surface temperatures was investigated. Both direct and inverse finite volume techniques were investigated and compared with the 1D semi-infinite method. In regions without significant spatial temperature gradients, 1-D techniques provided accurate aeroheating rates. The use of time correction with 1-D semi -infinite results did not produce satisfactory results for this low heating test on a slender body. The 1-D inverse finite volume technique resulted in time-invariant heating rates which all the other techniques' results eventually approached. In regions with sharp temperature gradients due to the striation patterns 2-D finite volume techniques were necessary to obtain accurate heating rates. The use of the onedimensional technique resulted in differences of $\pm 20 \%$ in the calculated heating rates in the vicinity of vortices because it did not account for lateral heat conduction in the model.

\section{Acknowledgements}

This experimental effort was accomplished with the help of many dedicated individuals, a few of which are mentioned here. Testing was accomplished with the support of G. Gleason, R. Hatten, H. Stotler, K. Hollingsworth, and R. Merski.

\section{$\underline{\text { References }}$}

1. Miller, C. G. III, “Comparison of Thin-Film Resistance Heat-Transfer Gages with Thin-Skin Transient Calorimeter Gages in Conventional Hypersonic Wind Tunnels," NASA TM-83197, December 1981.

2. Merski, N. R., "Global Aeroheating Wind-Tunnel Measurements Using Improved Two-Color Phosphor Thermography Method," Journal of Spacecraft and Rockets, Vol. 36, No. 2, 1999, pp. 160-170.

3. Puram, C. K., Daryabeigi, K., and Burkett, C. G. Jr., "Measurement of Steady and Unsteady Temperatures Using Infrared Thermography," Fundamental Experimental Measurements in Heat Transfer, ASME HTD-Vol. 179, 1991, pp. 23-29.

4. Daryabeigi, K., "Global Surface Temperature/Heat Transfer Measurements Using Infrared Imaging," AIAA 92-3959, July 1992.

5. De Luca, L., Cardone, G., and Carlomagno, G. M., "Experimental Investigation on Goertler Vortices in Hypersonic Flow," Computational Methods and Experimental Measurements VI, Vol. 1: Heat and Fluid Flow, Computational Mechanics Publications, Southampton, 1993, pp. 413-427.

6. Throckmorton, D. A., Zoby, E. V., Duvant, J. C., and Myrick, D. L., "Shuttle Infrared Leeside Temperature Sensing (SILTS) Experiment - STS28 Preliminary Results," AIAA 90-1741, June 1990.

7. Blanchard, R. C., Anderson, B. P., Welch, S. S., Glass, C. E., Berry, S. A., Merski, N. R., Banks, D. W., Tietjen, A., and Lovern, M., "Shuttle Orbiter Fuselage Global Temperature Measurements from Infrared Images at Hypersonic Speeds," AIAA 2002-4702, August 2002.

8. Cook, W. J., and Felderman, E. J., "Reduction of Data from Thin Film Heat Transfer Gages: A Concise Numerical Technique," AIAA Journal, Vol. 4, No. 3, 1966, pp. 561-562.

9. Hollis, B. R., "User's Manual for the OneDimensional Hypersonic Aero-Thermodynamic 
(1DHEAT) Data Reduction Code," NASA CR 4691, August 1995.

10. Daryabeigi, K., Huebner, L. D., "Heating Rate Measurements in Hyper-X Wing Gap," NASA TM-2002-211740, July 2002.

11. Walker, D. G., Scott, E. P., and Nowak, R. J., "Estimation Methods for Two-Dimensional Conduction Effects of Shock-Shock Heat Fluxes," Journal of Thermophysics and Heat Transfer, Vol. 14, No. 4, 2000, pp. 533-539.

12. Berry, S. A., Auslender, A. H., Dilley, A. D., and Calleja, J. F., "Hypersonic Boundary-Layer Trip Development for Hyper-X," Journal of Spacecraft and Rockets, Vol. 38, No. 6, pp. 853-864, 2001.

13. Micol, J. R., "Langley Aerothermodynamic Facilities Complex: Enhancements and Testing Capabilities," AIAA Paper 98-0147, January 1998.

14. Modest, M. F., Radiative Heat Transfer, McGrawHill, New York, 1993.

15. Hollis, B. R., Horvath, T. J., Berry, S. A., Hamilton, H. H. II, and Alter, S. J., "X-33 Computational Aeroheating Predictions and Comparisons with Experimental Data," Journal of Spacecraft and Rockets, Vol. 38, No. 5, 2001, pp. 658-669.

16. Anderson, D. A., Tannehill, J. C., and Pletcher, R. H., Computational Fluid Mechanics and Heat Transfer, Hemisphere Publishing, Washington, 1984.

17. Özisik, M. N., and Orlande, H. R. B., Inverse Heat Transfer: Fundamentals and Applications, Taylor \& Francis, New York, 2000.

18. Fay, J. A., and Riddell, F. R., "Theory of Stagnation Point Heat Transfer in Dissociated Air," Journal of The Aeronautical Sciences, Vol. 25, No. 2, 1958, pp. 73-85.

19. Yan, X. T., "On the Penetration Depth in Fourier Heat Conduction," AIAA 2002-2881, June 2002.

20. Smith, R. H., Scott, E. P., and Ligrani, P. M., "Experimental Validation of an Inverse Heat Conduction Problem Using Thermocouple and Infrared Data," AIAA 2001-0507, January 2001.
Table 1 Nominal tunnel flow conditions

\begin{tabular}{ccccccc}
\hline \hline $\begin{array}{c}\text { Run } \\
\text { Number }\end{array} \times 10^{6} / \mathrm{m}$ & $\mathrm{Me}_{\infty}$ & $\begin{array}{c}\mathrm{P}_{\mathrm{t} 1} \\
\mathrm{MPa}\end{array}$ & $\begin{array}{c}\mathrm{T}_{\mathrm{t} 1} \\
\mathrm{~K}\end{array}$ & $\begin{array}{c}\mathrm{H}_{\mathrm{t} 1} \\
\mathrm{KJ} / \mathrm{kg}\end{array}$ & $\begin{array}{c}\mathrm{P}_{\mathrm{t} 2} \\
\mathrm{Mpa}\end{array}$ \\
\hline 70 & 7.34 & 5.94 & 0.864 & 503.4 & 506.9 & 0.027 \\
71 & 7.36 & 5.94 & 0.865 & 503.9 & 506.4 & 0.027 \\
\hline \hline
\end{tabular}

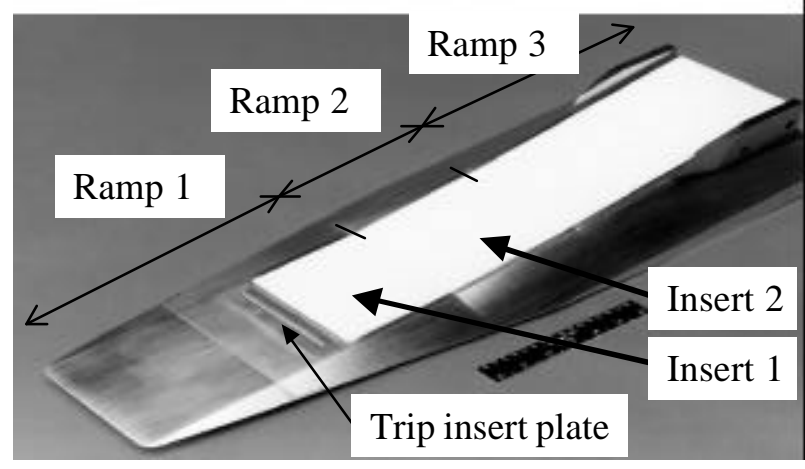

Figure 1. Photograph of 0.333-scale Hyper-X forebody model with Macor inserts.

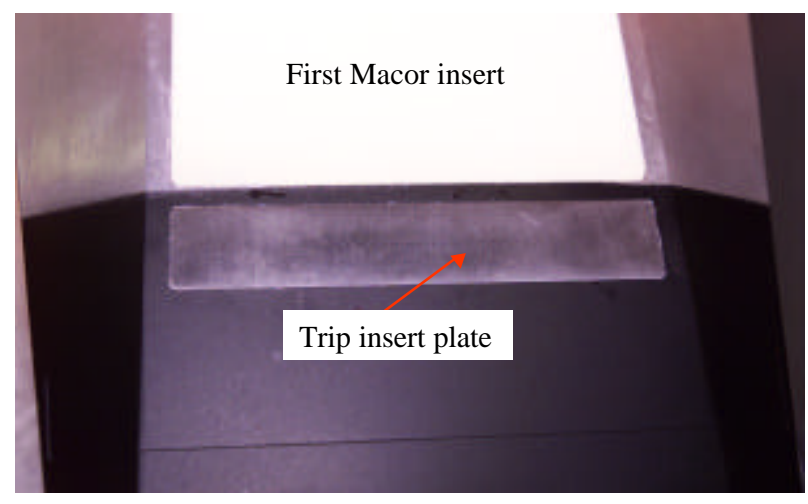

Figure 2. Photograph of trip insert plate with 17 orifices and first Macor insert on the Hyper-X forebody model. 


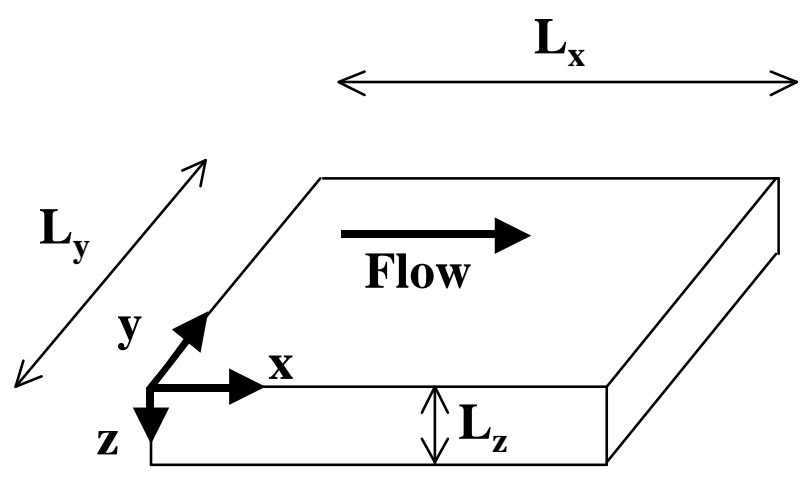

Figure 3. Coordinate system and geometrical definitions for the first Macor insert.

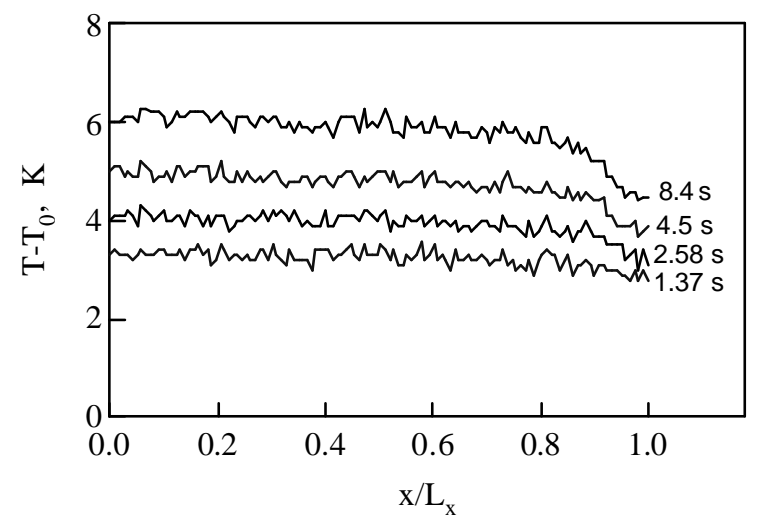

Figure 4. Spatial variation of temperature along first Macor insert centerline $\left(y=\mathrm{L}_{\mathrm{y}} / 2\right)$ at various times.

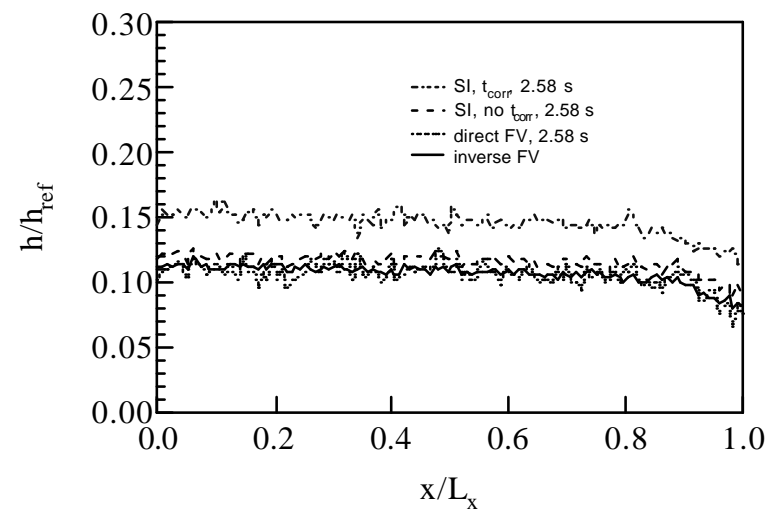

Figure 5. Spatial variation of aeroheating rate along first Macor insert centerline using various techniques.

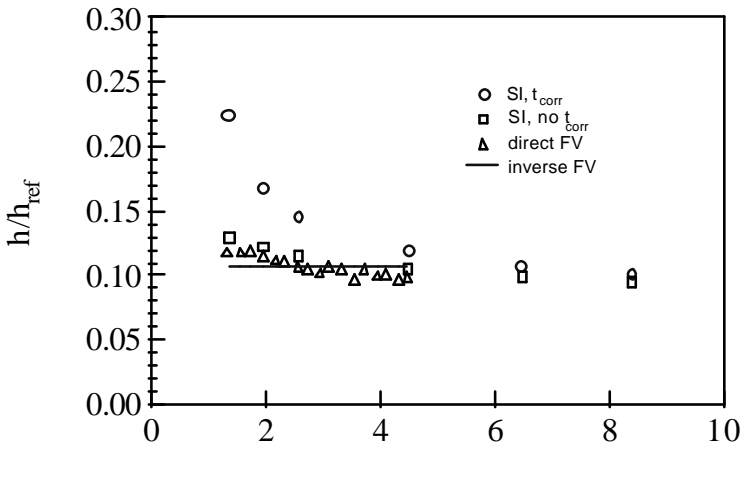

$\mathrm{t}, \mathrm{s}$

Figure 6. Temporal variation of spatially averaged aeroheating rate $\left(0 \leq \mathrm{x} / \mathrm{L}_{\mathrm{x}} \leq 1.0\right)$ along $1^{\text {st }}$ Macor insert centerline using various techniques.

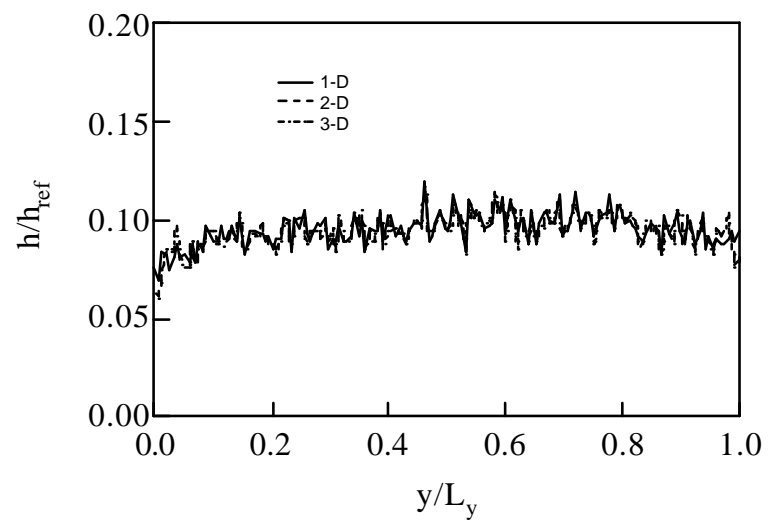

Figure 7. Comparison of 1-D, 2-D and 3-D direct finite volume techniques at $\mathrm{x} / \mathrm{L}_{\mathrm{x}}=0.75$ at $\mathrm{t}=2.58 \mathrm{~s}$ for baseline test without gas injection.

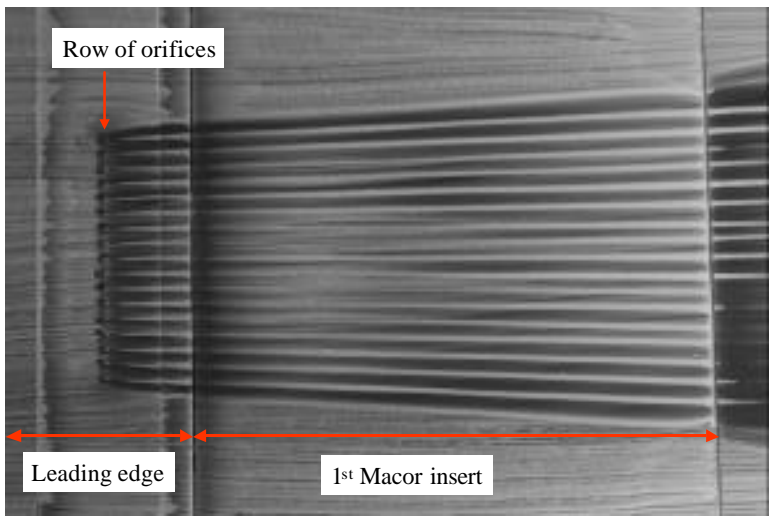

Figure 8. Oil flow photograph 


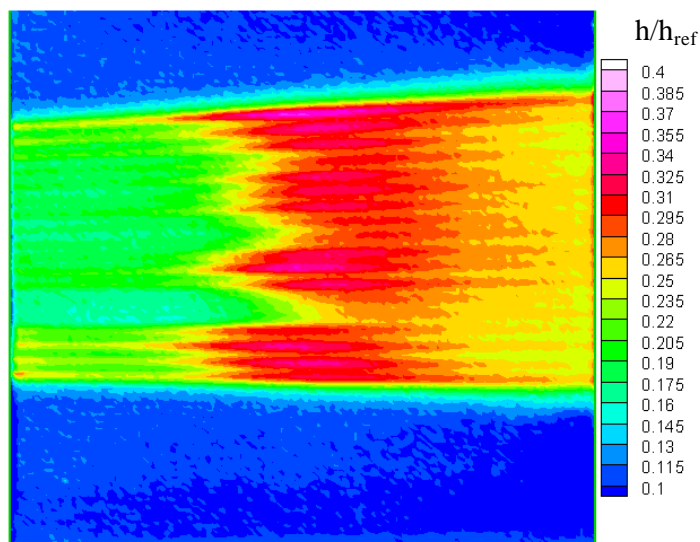

Fig 9. Spatial variation of aeroheating rates for test with gas injection using 1-D inverse finite volume technique.

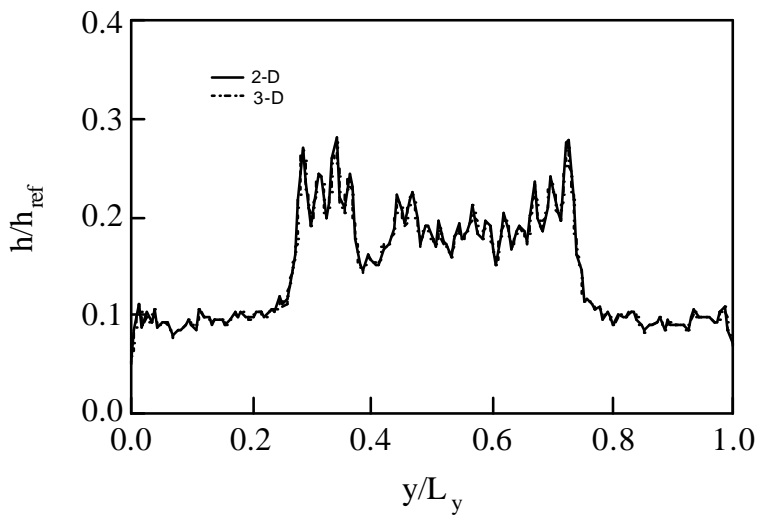

Figure 10. Comparison of 2-D and 3-D direct finite volume results at $\mathrm{x} / \mathrm{L}_{\mathrm{x}}=0.25$ for test with gas injection

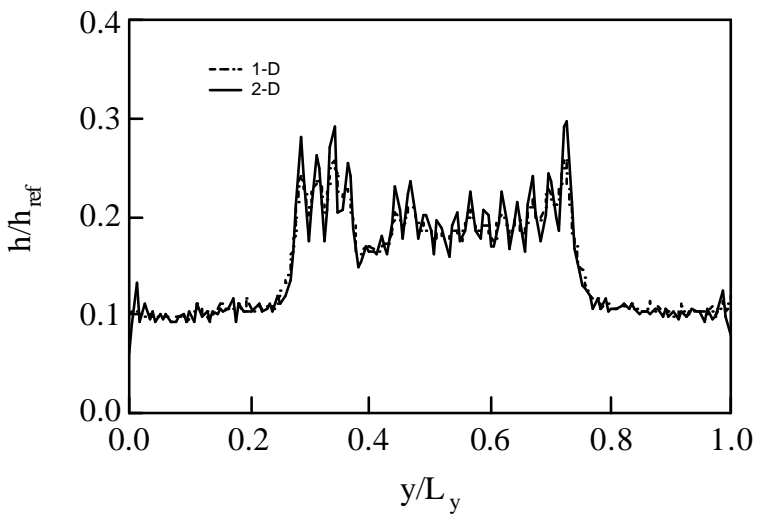

a)

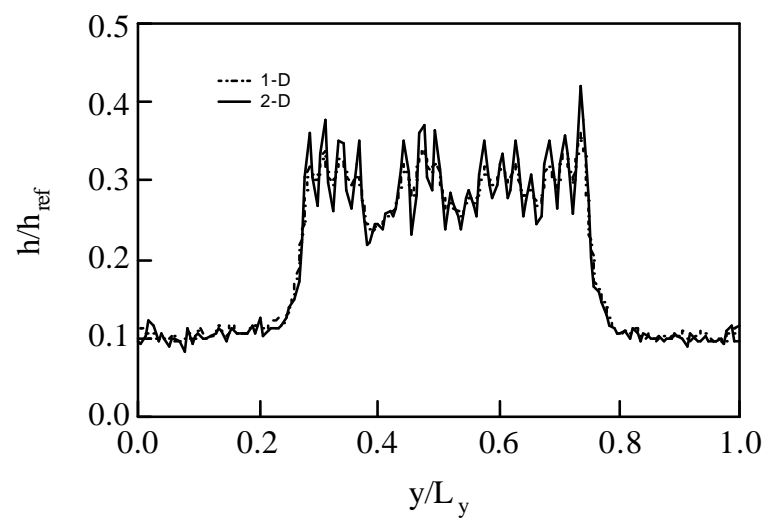

b)

Figure 11. Comparison of 1-D and 2-D inverse finite volume aeroheating results for test with gas injection at $\mathrm{x} / \mathrm{L}_{\mathrm{x}}=$ a) 0.25, b) 0.5

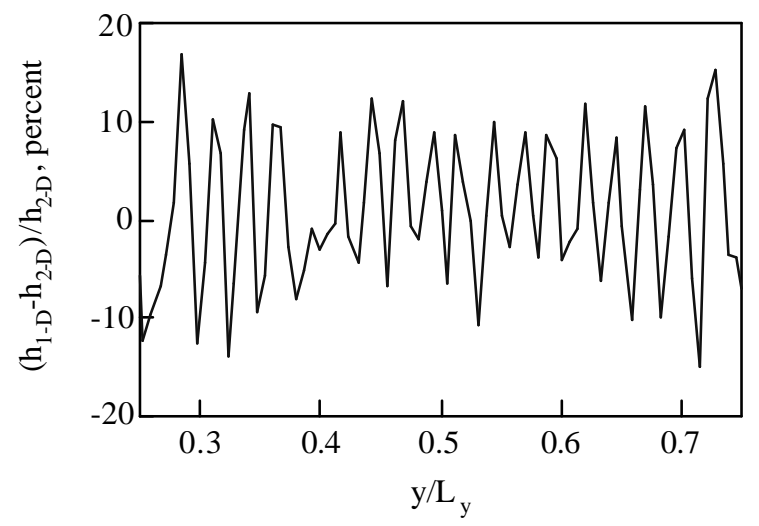

a)

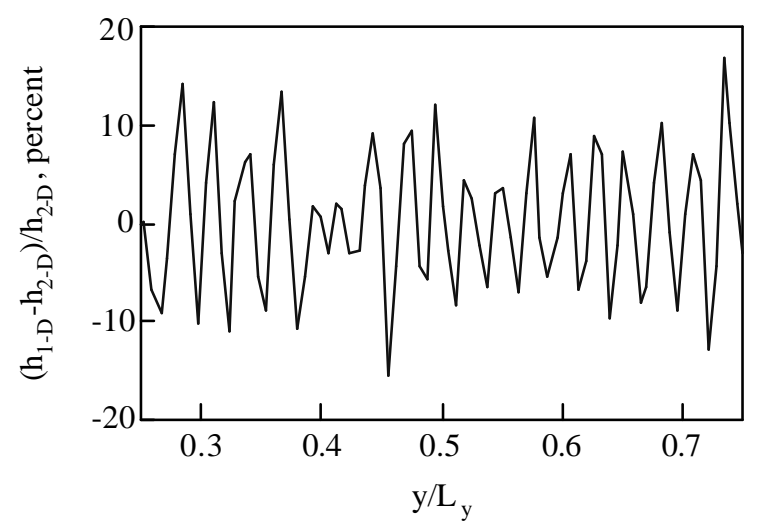

b)

Figure 12. Relative difference between 1-D and 2-D inverse finite volume aeroheating results for test with gas injection at $x / L_{x}=$ a) 0.25, b) 0.5 